\title{
RÉGIMEN DE DESIGUALDAD Y PUEBLOS INDÍGENAS EN EL PERÍODO POSTDICTATORIAL. TRES VÍAS EN LA DISPUTA POR LA IGUALDAD ${ }^{1}$
}

\author{
Mayarí Castillo², Claudio Espinoza ${ }^{3}$ y Luis Campos ${ }^{4}$
}

\begin{abstract}
Resumen
Este artículo busca comprender la situación de desigualdad histórica que marca la relación entre mundo indígena y sociedad nacional, mostrando sus principales modificaciones a partir del período postdictatorial. Explora cómo a partir de ese período, aun cuando el régimen de desigualdad chileno ha establecido marcos estrechos para revertir situaciones de desigualdad, los pueblos indígenas han logrado modificarlos. Para esto presenta tres ejemplos: la vía política institucional, la vía etnogenética y la vía socioambiental, explorando las estrategias específicas de estos pueblos para revertir estas situaciones, ya sea a través de la conquista del poder politico institucional, del reconocimiento cultural o a partir del control de los recursos naturales estratégicos.
\end{abstract}

Palabras claves: Pueblos indígenas - desigualdad - política institucional - etnogénesis - conflictos socioambientales - Chile. serticle tries to understand the historical situation of inequality which marks the relationship between the indigenous world and national society, showing the main changes for the post-dictatorship period. It explores how from that period, even though the inequality regime in Chile has established close frameworks to reverse situations of inequality, indigenous peoples have achieved to challenge them. To illustrate this process, the paper presents three examples: the political way, the ethnogenetic way and socio-environmental way, exploring the specific strategies of the indigenous people to reverse these situations, through the achievement of institutional political power, cultural recognition or from getting of control strategic natural resources.

Keywords: Indigenous people - inequality - institutional policy - ethnogenesis - environmental conflicts - Chile.

Recibido: septiembre 2015. Aceptado: agosto 2016.

\section{$*$ Introducción}

Uno de los problemas sobre los que más se ha discutido en Chile y América Latina durante las últimas décadas es el de los altos niveles de desigualdad existentes en nuestra región. En este debate, la investigación social se ha visto constantemente interpelada a entregar respuestas, con lo que se ha desarrollado una abundante investigación empírica al respecto. Sin embargo, esta pesquisa ha transitado mayormente por un camino separado del de la investigación realizada en torno a la realidad de los pueblos indígenas, aspecto tan central en el contexto latinoamericano. La investigación empírica se ha centrado en el ingreso y la ocupación a nivel general (Filgueira 2000), mientras que la tradición de los estudios sobre pueblos indígenas se ha focalizado en establecer su situación de

1 Investigación financiada por el Centro Interdisciplinario de Estudios Interculturales e Indígenas-ICIIS, Código de Proyecto CONICYT/FONDAP 15110006; Proyecto FONDECYT de Iniciación 11140008; Proyecto FONDECYT de Iniciación 11130002 , y Proyecto FONDECYT Regular 1150876.

2 Escuela de Antropología, Universidad Academia de Humanismo Cristiano - Centro Interdisciplinario de Estudios Interculturales e Indígenas-ICIIS. Dirección Postal: Condell 506, Providencia, Santiago, CHILE. Email: mayari.castillo@gmail.com

3 Escuela de Antropología, Universidad Academia de Humanismo Cristiano - Centro Interdisciplinario de Estudios Interculturales e Indígenas-ICIIS. Dirección Postal: Condell 506, Providencia, Santiago, CHILE. Email: cespinoza@academia.cl

4 Escuela de Antropología, Universidad Academia de Humanismo Cristiano - Centro Interdisciplinario de Estudios Interculturales e Indígenas-ICIIS. Dirección Postal: Condell 506, Providencia, Santiago, CHILE. Email: lcampos@academia.cl 
pobreza (Agostini et al. 2010; Cimadamore et al. 2006; CEPAL 2012; CONEVAL 2012), encontrando problemas para relacionar esta pobreza persistente con las dinámicas de carácter más general, propias de las sociedades desiguales de la región.

En este marco, el artículo busca establecer un puente entre ambas tradiciones, con el fin de entregar herramientas que permitan comprender el mundo indígena contemporáneo a partir de una relación desigual de carácter histórico con la sociedad en la que se inserta, misma que ha delimitado esta posición de pobreza persistente. Esta relación se ha ido modificando a lo largo del tiempo a partir de la acción de varios actores, tales como el Estado, movimientos sociales y pueblos indígenas, por nombrar los más relevantes. Este trabajo se enfoca en el rol de estos últimos en tales procesos, para lo cual analiza de manera general algunas experiencias ilustrativas con el fin de mostrar cómo los pueblos indígenas, aunque no sin dificultades, han podido modificar algunos aspectos claves de esta relación desigual.

Comprendemos que los regímenes coloniales y los patrones desiguales instalados a partir de éstos, constituyen el punto de inicio de un proceso que tiene continuidad a lo largo del tiempo y que ha persistido bajo diversas expresiones dependiendo de cada momento histórico. Durante este proceso se ha ido articulando la expulsión de la población indígena de ciertos territorios mediante una "desposesión" sistemática, que opera a través de la pérdida del control de recursos que antes les pertenecían o eran administrados por ellos (Bebbington y Bebbington 2009). Ambos hechos han repercutido en que la situación de los pueblos indígenas en las sociedades contemporáneas no pueda ser analizada solamente desde conceptos como la pobreza o la pobreza rural, sino que requiere de una mirada que sitúe en el centro de la reflexión el concepto de desigualdades, entendiendo que éste nos permite ampliar el foco de la investigación más allá de la condición específica de pobreza y puntualizar en la relación histórica entre pueblos indígenas y sociedad nacional que la ha producido. Establecemos así una relación específica para el caso de los pueblos indígenas entre ambos conceptos, basada en la noción de producción de pobreza (Cimadamore 2006) que enfatiza las dinámicas del conjunto de la sociedad, que repercuten en la existencia y reproducción de la pobreza en grupos específicos. A la vez, el uso del concepto de "desigualdades" por el de "desigualdad", nos permite visibilizar que esta relación comprende las diversas variables que configuran situaciones diversas, tales como la clase, el género, lo rural/ urbano. Esto forma parte de un esfuerzo por entender a los sujetos indígenas como heterogéneos tanto en términos de posiciones estructurales como a nivel cultural y político, lo que adquiere una importancia particular cuando nos enfrentamos a pueblos que no constituyen actores monolíticos, sino que deben ser analizados desde la pluralidad de actores que los componen.

Siguiendo esta línea de análisis, consideramos esta relación histórica como parte de un régimen de desigualdad (Costa 2015; Acker 2006), concepto teórico que implica observar nuestra sociedad como una matriz societal anclada en desigualdades históricas que encuentran expresión y reproducción no solo en aspectos relacionados con la distribución de recursos, sino también en otras dimensiones, como la dimensión sociopolítica y jurídica, los discursos científicos y coloquiales, las imágenes/ estereotipos culturales, entre otros aspectos. Pensar las sociedades desiguales desde este lugar, implica superar aquellas visiones que entienden los estudios de la desigualdad centrados en variables como la ocupación y los ingresos, y ampliar la agenda de investigación a todos aquellos aspectos cotidianos e institucionales que se ven involucrados en la persistencia de los altos niveles de desigualdad observados en nuestro país. Estos elementos, tal y como ha señalado Costa (2015), hacen del régimen de desigualdad una formación social de difícil modificación, ya que muchos de sus mecanismos operan en el día a día, de manera simultánea y en distintos niveles, cristalizando situaciones de acceso desigual a recursos/ bienes y otorgándoles legitimidad ante los ojos de gran parte de la población.5 Pese a lo difícil de su modificación, la noción de régimen de desigualdad nos permite ver cómo estos mecanismos simultáneos muchas veces dejan intersticios en los cuales la acción de los desaventajados puede introducir modificaciones. Esto, porque los actores e instituciones involucrados no constituyen entes monolíticos con cursos de acción lineal y completamente coherentes, sino que muchas veces presentan estructuras y formas de acción intermitentes y contradictorias.

\footnotetext{
5 Para más detalles sobre la noción de régimen de desigualdad, véase Costa 2015.
} 
Esto resulta particularmente evidente si observamos uno de los actores que por excelencia debe ser incluido en el análisis, el Estado. Con sus diversas instituciones, al relacionarse con la población indígena genera muchas veces intervenciones en direcciones opuestas, contradictorias o simplemente inesperadas.

Es precisamente dentro de este marco que el artículo busca examinar cómo, a pesar de que este régimen de desigualdad ha establecido estrechos límites para la ampliación del acceso a los recursos valorados, ciertos grupos al interior de los pueblos indígenas han desafiado y/o modificado esta situación. Para esto explora, a modo de ejemplo, tres procesos relevantes en esta línea: la vía política institucional, la vía etnogenética y la vía socioambiental. Cada uno de ellos apunta a estrategias específicas de grupos pertenecientes al pueblo mapuche, atacameño/likan antai, diaguitas, changos y afrodescendientes para revertir situaciones de desigualdad persistente, ya sea a través del logro del poder político, del reconocimiento o del control de los recursos naturales. Si bien en términos analíticos se plantean como estrategias distintas y lineales en el tiempo, evidentemente son procesos que deben comprenderse como entrecruzados en el marco de contextos culturales complejos y conflictivos y, por ello, muchas veces contradictorios. De la misma forma, tampoco deben ser comprendidas como estrategias de pueblos indígenas en su totalidad, sino de ciertos sectores específicos al interior de éstos. ${ }^{6}$

El artículo toma como punto de partida la década de 1990, pues se trata de un momento en el cual se observan dos cambios importantes: en primer lugar, en los patrones distributivos como consecuencia de las modificaciones estructurales de la década de 1980 y, en segundo lugar, importantes cambios políticos y legales que van a

$6 \mathrm{Al}$ respecto, cabe señalar que los pueblos indígenas constituyen grupos humanos complejos y diversos, sobre todo si se analizan sus cursos de acción a largo plazo y en el marco de un conflicto. Por esta razón, para efectos de este artículo analizamos las experiencias de ciertos sectores al interior de los pueblos indígenas mencionados. En ese sentido, el análisis no pretende exhaustividad sobre la totalidad de los pueblos indígenas de nuestro país ni mucho menos en relación con la heterogeneidad que compone a cada uno de éstos, sino que analiza experiencias específicas de luchas por la igualdad durante el período postdictatorial que pueden ser ilustrativas para el argumento. reconfigurar de manera importante el régimen de desigualdad y la posición de los pueblos indígenas al interior de éste. Ambos procesos se revisan brevemente en una primera parte, donde se establecen los elementos generales de la situación de desigualdad y pobreza para los pueblos indígenas en este período, centrándonos en particular en la precarización de sus economías por la modificación de la matriz económica nacional, tributaria de los cambios introducidos a partir de los "ajustes estructurales".

Luego de este diagnóstico inicial, se da paso al análisis de lo que hemos llamado tres vías en la disputa por la igualdad, comenzando con aquella vinculada a la disputa por el poder político por parte del pueblo mapuche, para luego considerar las estrategias etnogenéticas en la disputa por el reconocimiento en el caso diaguita y de otros procesos que han emergido en el último tiempo, como los de los indígenas urbanos, los changos en la región de Atacama y los afrodescendientes en Arica. Para finalizar, se analizan los recientes conflictos que tienen en su centro la propiedad y el uso de recursos naturales estratégicos de los territorios indígenas, enfatizando el caso del pueblo atacameño. A partir del análisis de estas distintas experiencias buscamos poner en relieve el rol de los sujetos indígenas, quienes a través de estas acciones han ido reescribiendo una historia plagada de deudas históricas, con el fin de establecer la importancia del papel futuro de los pueblos indígenas en el debate y la reconfiguración activa de las relaciones con la sociedad nacional con miras a la construcción de una sociedad más igualitaria.

\section{* Desigualdad, pobreza y pueblos indígenas EN LA POSTDICTADURA}

Hasta la década de 1990, la situación de los pueblos indígenas en Chile presentaba condiciones de aguda exclusión en el contexto de una sociedad con altos niveles de pobreza en general. A pesar de que durante gran parte del siglo XX Chile mostró una tendencia redistributiva importante, los altos niveles de pobreza seguían siendo un problema hacia finales de la década de 1970, aun en contra de las políticas focalizadas al respecto.

Este problema se agudizó a partir de los cambios aplicados en el marco de los ajustes estructurales consolidados durante la década de 1980, los que elevaron de manera crítica las cifras de pobreza en el contexto de una de las 
peores crisis de nuestro país (Martínez y Tironi 1985; Atria 2004; León y Martínez 2001). A partir de estas políticas la reorientación de la matriz económica chilena pretendió revertir ciertos movimientos redistributivos que habían estado en marcha durante el período desarrollista, y que fueron interrumpidos y revertidos a partir del golpe militar. Fenómenos como la concentración de la propiedad de la tierra, la riqueza, el mejoramiento de las condiciones salariales y de empleo, el aumento de los niveles de calificación de los segmentos en la base de la estratificación, entre otros procesos que habían sido impulsados a través de políticas públicas concretas, fueron interrumpidos a partir de este período, aplicándose políticas específicas destinadas a revertirlos.

En ese sentido, existe consenso entre los expertos en señalar que a partir de estos cambios no solo hay un aumento en los niveles de pobreza a nivel nacional, sino también un aumento paulatino de los niveles de desigualdad en nuestro país, que acabará situándolo al poco tiempo entre los más desiguales de la región (León y Martínez 2001; Portes y Hoffmann 2003; Torche y Wormald 2007). Hacia principios de la década de 1990 ya son patentes los primeros cambios más consolidados de estas tendencias: altos niveles de pobreza y extrema pobreza muy focalizados territorialmente a nivel urbano y rural, un deterioro de las condiciones generales de empleo y de los ingresos de los segmentos en la base de la estratificación social (León y Martínez 2001; Portes y Hoffmann 2003) y uno de los mayores niveles de concentración de la riqueza de la región (Espinoza 2006), por nombrar algunos de los más relevantes para efectos de este artículo. Esta situación afectó particularmente a los pueblos indígenas.

Los pueblos indígenas ya se encontraban en una posición de extrema vulnerabilidad debido a los procesos de expansión y ocupación territorial implementados por el Estado chileno desde mediados del siglo XIX y hasta principios del siglo XX (CVHYNT, 2008), y que conforman el marco general a partir del cual se establece la relación entre sociedad nacional contemporánea y pueblos indígenas.

En el caso del norte, este proceso adquirió, en términos generales, el nombre oficial de "Chilenización del norte" (Aylwin et al. 2013) y supuso la pérdida de control, por parte de los pueblos indígenas, sobre recursos estratégicos como el agua y territorios ricos en recursos mineros, los que pasaron a formar parte de empresas estatales en el marco del desarrollismo. En el caso del centro-sur del país, este proceso es conocido comúnmente con el nombre de "Pacificación de la Araucanía", e implicó una drástica reducción de las tierras comunales cultivables en la mayor parte de los territorios involucrados (Bengoa 2000 [1985]: 324). Este empobrecimiento histórico y progresivo al que fueron sometidos los diferentes pueblos indígenas del país provocó que a partir de la década de 1980 los aumentos de niveles de pobreza a nivel general los golpearan con más fuerza que a otros sectores. Fueron afectados no tan solo por el cambio de la orientación de la economía, que redujo drásticamente el mercado de productos agrícolas, su principal actividad económica (Bengoa y Valenzuela 1984), sino que también fueron impactados por dispositivos jurídicos específicos promulgados durante la dictadura cívico-militar, que formaron parte sustancial de estos cambios estructurales y que tuvieron efectos particularmente negativos en las comunas rurales con altos porcentajes de población indígena. Tal es el caso de legislaciones como el Decreto Ley 2568 sobre Tierras Comunales, la Ley Orgánica Constitucional de Concesiones Mineras de 1982, el Decreto con Fuerza de Ley 1122 de 1981 (Código de Aguas) y el Decreto Ley 701 de 1974 sobre Fomento Forestal. Todos ellos estuvieron orientados a modificar la estructura agraria de nuestro país con miras al establecimiento de incentivos para la inversión privada en zonas estratégicas a partir de la concentración de la propiedad de la tierra y la explotación de los recursos naturales.

En el caso del Norte Grande y el Norte Chico, resultaron particularmente relevantes la Ley Orgánica Constitucional de Concesiones Mineras de 1982 y el DFL 1122 de 1981 (Código de Aguas), que incentivaron la expansión de la minería y la especulación sobre el escaso recurso hídrico de la zona (Prieto y Bauer 2012; Bauer 2009, 2002; Budds 2004, 2007, 2009). En este mar$\mathrm{co}$, muchas de las comunidades de la zona perdieron sus derechos de agua, zonas de pastoreo y transhumancia (Yáñez y Molina 2008, 2011), lo que desencadenó una importante migración desde las zonas altas a los centros urbanos, como Calama, Antofagasta, Iquique y La Serena. Hoy en día, las comunas rurales que albergan a las antiguas comunidades indígenas muestran importantes 
signos de despoblamiento y gran parte de la población que se autoidentifica como indígena en la zona reside en los grandes centros urbanos del norte del país. Al respecto, INE-Orígenes (2005) destaca que 78,5\% de los aymaras viven en zonas urbanas, mientras que entre los atacameños la cifra alcanza $82,8 \%$. Coincidente con este fenómeno, las comunas que muestran los mayores índices de pobreza en estas regiones son precisamente estos centros urbanos.

En el caso del centro-sur de Chile, el DL 701 de 1974 sobre Fomento Forestal y la Ley 2568 sobre Tierras Comunales fueron particularmente determinantes para la actual situación de los pueblos indígenas (Rupailaf 2002). En conjunto con una modificación del mercado agropecuario que afectó duramente a la producción de las comunidades indígenas, ambos aparatos jurídicos favorecieron la concentración de la tierra y la reorientación de la economía de la zona a la exportación internacional de materias primas a cargo de inversión privada transnacional. Esto provocó la alteración de la economía doméstica indígena, la pauperización de las comunidades y aceleró el proceso de migración interna ya iniciado en décadas anteriores. Hoy, la mayor parte de la población indígena perteneciente a estos territorios reside en centros urbanos como Temuco y Santiago. En el caso de esta última ciudad, la población que se reconoce como indígena se concentra precisamente en las zonas del cordón periférico con las tasas más altas de pobreza y los mayores niveles de segregación espacial, tales como La Pintana, Huechuraba, Pudahuel, Renca y Lo Prado (Censo 2002). Cabe también destacar que las zonas afectadas por el Decreto 701 son las que han mantenido los peores indicadores de pobreza desde el inicio de la transición hasta hoy. Los casos de Tirúa, Lumaco, Cañete, entre otros, son ejemplo de ello. Es posible afirmar entonces que estas legislaciones, incrustadas con las últimas modificaciones en el régimen de desigualdad chileno, se constituyeron en mecanismos claves para la reproducción de las posiciones desiguales de los pueblos indígenas en el marco del proyecto nacional.

De esta manera, a principios de la década de 1990, los pueblos indígenas se encontraban en una situación sumamente precaria (Agostini et al. 2010) y, a pesar de que a partir del llamado período transicional se aplicaron sistemáticas políticas de reducción de la pobreza y la extrema pobreza a nivel general, la situación de los pueblos indígenas no fue abordada en términos específicos sino hasta la promulgación de dos nuevos elementos en el ordenamiento jurídico: la Ley Indígena 19.253 y la CONADI, ambos generados a partir de la presión acumulativa de las organizaciones indígenas desde mediados de los ochenta en adelante. Esta presión llevó a las fuerzas políticas opositoras al régimen militar a acoger en su programa de gobierno sus demandas, cuestión que quedó sellada en el Pacto de Nueva Imperial de 1989, entre el entonces candidato a la presidencia Patricio Aylwin y las organizaciones y comunidades indígenas. Este pacto se tradujo concretamente en las dos instancias mencionadas: la Ley Indígena 19.253, aprobada en 1993, que impuso al Estado el respeto, la protección y la promoción de los derechos y las culturas indígenas y sus tierras (Ley Indígena 19.253 , artículo $1^{\circ}$ ), y la creación, a través de la misma ley, de la Corporación Nacional de Desarrollo Indígena (CONADI), entre cuyas tareas principales se establece la restitución y la compra de tierras para las comunidades afectadas por la pérdida de ellas.

Pese a sus múltiples falencias, la Ley Indígena permitió posicionar la temática indígena en el Estado mismo, otorgando un marco para el reconocimiento de los derechos de las minorías étnicas del país (Campos 2008). A partir de ese momento puede hablarse del inicio de políticas multiculturales por parte del gobierno chileno, en el sentido de las definiciones expuestas por algunos liberales comunitaristas (Kymlicka 1996; Taylor 1993) sobre el manejo de las diferencias culturales en el espacio público a través del otorgamiento de derechos específicos basados en el reconocimiento de estas diferencias culturales, al igual como sucedió en otros países del continente (Agudelo y Recondo 2007). En este escenario, y tal cual lo ha señalado Habermas (1999), los movimientos de emancipación en las sociedades multiculturales no configuran un fenómeno unitario $y$, dependiendo de sus fases, la lucha por el reconocimiento puede estar dirigida tanto a la reivindicación de la diferencia más radical como también a la búsqueda de la igualdad, asegurando así los derechos no reconocidos hasta entonces a esos grupos diferenciados.

La promulgación de la Ley Indígena marcó un punto de inflexión en la situación de los pueblos indígenas. No solo porque apuntaló parte de sus propios procesos políticos y culturales tributarios de la década de 1980, sino 
porque estableció mecanismos específicos de disputa por recursos socialmente valorados, tales como el territorio, el agua y el subsuelo. Si bien no tuvo carácter retroactivo, permitió a algunas comunidades resolver e impugnar situaciones de abuso de larga data.? Su criticada imperfección y el escaso alcance de este artefacto jurídico no impidieron que se haya constituido en uno de los principales espacios intersticiales a partir de los cuales los sujetos indígenas han ido encajando sus distintas estrategias en la disputa por la igualdad y el reconocimiento.

Hay que señalar, sin embargo, que no todo fue avance a partir de esta incipiente política multicultural. Durante gran parte del período transicional, y al igual como ocurrió en el resto de la región, el Estado se mostró proclive a priorizar ciertos procesos de reconocimiento y ciertos derechos estratégicos, pero no entró en el debate sobre la redistribución, dejando pendientes cuestiones centrales relativas a la pobreza y la desigualdad económica. Así, por ejemplo, desde la conformación de la CONADI, el lento avance del proceso de restitución de tierras y aguas provocó distintas reacciones al interior del movimiento indígena, fortalecido tanto por el nuevo contexto político institucional como por la emergencia de un movimiento indígena de magnitud a nivel latinoamericano. En este marco, muchas comunidades indígenas, tanto constituidas legalmente a partir de la legislación indígena como otras que no lo estaban, comenzaron a presionar a los gobiernos a través de la ocupación de las tierras sobre las que tenían claridad de posesión y respecto a las cuales las vías institucionales mostraban escasos avances. En otros casos emprendieron acciones judiciales concretas por reparación y/o protección frente a actores privados o estatales presentes en sus territorios, a la vez que comenzaron a emerger o consolidarse organizaciones que demandaron el reconocimiento como pueblo y/o nación en el marco de la legislación vigente (Campos 2002; Mella 2001). Así, como podremos ver en los próximos apartados, desde ese momento ciertos grupos al interior de

\footnotetext{
7 Un ejemplo de esto es el caso de las comunidades atacameñas de Toconce y su disputa con la minería por la propiedad y el uso de las vegas de Turi, uno de los primeros fallos positivos obtenidos en el marco de acciones judiciales emprendidas por las comunidades a partir del reconocimiento otorgado al territorio en la Ley Indígena. Para más detalles sobre este caso, léase el fallo completo disponible en: http://www.conadi.gob.cl/avances_en_desarrollo_indigena/sentencia.pdf (consultado el 28.08.2015).
}

los pueblos indígenas comienzan a utilizar los recursos del nuevo escenario postdictatorial para el logro de posiciones de mayor igualdad. Analizaremos en detalle estos procesos a continuación.

\section{* Voces desde la política. Pueblos indígenas EN LA DISPUTA POR EL PODER POLÍTICO INSTITU- CIONAL}

No cabe duda alguna que, dada las condiciones históricas que fijaron el marco de la relación entre el Estado y los pueblos indígenas, su participación política se ha conducido por un camino marcadamente desigual. Aunque existen interpretaciones que ven el origen de esta relación, primero colonial y luego republicana, en términos más simétricos y coprotagónicos (CVHYNT 2008: 298), lo cierto es que se trata de una relación que refleja de manera prístina una estructura desigual de poder. En este marco, y corroborando que el elemento distintivo de la organización política que caracteriza a la modernidad es que los diversos grupos sociales se ven obligados a concretar sus intereses dentro del dominio organizado por el Estado (Asad 1992), constatamos que una parte sustancial de la disputa por el poder político por parte de estos pueblos pasa por su incorporación a la estructura institucional del Estado. Es precisamente a través de la participación política donde podemos ver de manera privilegiada los intentos de modificar activamente patrones distributivos o posiciones de desventaja desde los actores, de ahí que el análisis de estas experiencias resulte importante.

Para ejemplificar esto se analizará el caso de la participación política mapuche, ${ }^{8}$ prestando especial atención a la participación electoral mapuche en el nivel municipal, entendiéndola como un componente de la acción política indígena (Iturralde 1998). Partiendo del hecho de que ciertos sectores mapuches han buscado históricamente establecer relaciones con el Estado y la sociedad nacional

\footnotetext{
8 Para efectos de este artículo se seleccionó el caso de organizaciones mapuches que, representando a algunos sectores de dicho pueblo, expresan de manera más evidente un tipo de estrategia con ciertos niveles de continuidad y consolidación durante las últimas tres décadas. Si bien existen también experiencias en esta línea en otros pueblos indígenas del país, parece ser que en tanto movimiento etnopolítico que buscó el control de los gobiernos locales, el caso mapuche es el que ofrece manifestaciones de mayor continuidad para el análisis pretendido.
} 
con el fin de alcanzar niveles de representación y acceso al poder, creemos que tanto en la primera mitad del siglo XX como en el período postdictadura, esta participación electoral mapuche ha intentado alcanzar cuotas de poder como una forma de revertir condiciones históricamente asimétricas. Esto se percibe con mayor claridad en la participación electoral municipal de las últimas décadas.

En estos términos, habría que partir señalando que si bien es cierto que los mapuches han permanecido mayormente en los márgenes del sistema político chileno, han existido intentos de participación efectiva desde la primera mitad del siglo XX en adelante. Estos intentos surgieron casi en paralelo con las organizaciones mapuches que, en aquellas primeras décadas, se conformaron como respuesta a las consecuencias que acarreó la ocupación de la Araucanía por parte del Ejército chileno y la posterior reducción territorial, ocurrida entre 1884 y 1929 (Foerster y Montecino 1988). Tales organizaciones prontamente entraron a contender en el escenario político nacional, y si bien diferían en muchos de sus planteamientos, mostraban un elemento común que tiene que ver con cierta adaptación de la sociedad mapuche a la lógica del Estado chileno para alcanzar sus objetivos. Es lo que Bengoa (1999) ha denominado como la lucha por la integración respetuosa de los mapuches a la sociedad chilena, queriendo señalar con ello el intento de las organizaciones mapuches por participar en plenitud de la vida política nacional, adoptando, coincidentemente, modos organizacionales análogos a los adoptados por las organizaciones chilenas de aquella época. Un segundo elemento compartido es que estos dirigentes habrían tenido plena conciencia de que el medio más viable para obtener cambios significativos para su pueblo era a través de la representación parlamentaria (Foerster y Montecino 1988). Se percibe, así, un temprano interés de organizaciones mapuche por participar en la contienda electoral nacional, camino que no será interrumpido sino hasta el golpe de Estado en 1973. De esta manera, y aunque no en número alto, se observa que ya desde la década de 1920 hay mapuches provenientes de organizaciones indígenas que participan en el Parlamento (Foerster y Montecino 1998; Cayuqueo 2006).

En cuanto a la participación mapuche en las contiendas electorales municipales, a pesar de que se ha sostenido lo contrario (Aylwin 2001; Cayuqueo 2006), la situación no es tan diferente. Los datos muestran que si bien es cierto que en términos cuantitativos las cifras no son abundantes, tampoco son despreciables y, más aún, que entre 1941 y 1971, el período predictatorial del cual se tiene registro sistemático, la presencia mapuche en los gobiernos locales se fue incrementando según se sucedieron las distintas elecciones. Es decir, aquella estrategia por insertarse a plenitud en la vida política nacional pareció ir consolidándose también en el nivel local. En 1935 se presentó a las elecciones municipales Herminia Aburto Colihueque, hija del dirigente mapuche Manuel Aburto Panguilef y secretaria de la Federación Araucana. No resultó electa, pero a partir de allí hubo una creciente presencia mapuche en estas contiendas electorales, mucha de la cual provenía de las organizaciones indígenas de la época. ${ }^{?}$

Lo cierto es que la situación de los mapuches en los gobiernos municipales no dista mucho de su presencia en las parlamentarias, esto es, una participación que se fue acrecentando con el tiempo, donde la mayoría de los regidores electos provenían de organizaciones mapuches $y$, al mismo tiempo, se presentaban por partidos políticos que cruzan todo el abanico electoral.

Esta situación llegó a su fin, como se dijo, con el golpe de Estado de 1973. A partir de allí cambió el escenario político del país y los mapuches no estuvieron ajenos a tales cambios. Este nuevo escenario provocó un cambio en las aproximaciones de la sociedad mapuche hacia el Estado y la sociedad nacional. Si hasta antes del golpe militar primaron los intentos de integración, después de esa fecha, y como producto de una serie de medidas que señalamos en el primer apartado, el movimiento indígena se caracterizó por el rechazo a la asimilación, por la afirmación de las propias características indígenas y por la separación de la cultura mapuche de la chilena (Bengoa 1999). A diferencia de lo que había ocurrido en épocas pasadas, cuando los mapuches se habían plegado a otras luchas sociales, a partir de la década de 1980 el movimiento se caracterizó por la distancia con otros grupos, remarcando su diferencia étnica y levantando reivindicaciones autonómicas.

9 Una investigación en curso (FONDECYT de Iniciación 11130002) nos permite afirmar que entre 1941 y 1971 hubo más de 90 regidores mapuches en comunas pertenecientes al territorio histórico mapuche, esto es en las actuales octava, novena, decimo cuarta y décima regiones. 


\section{Transición a la democracia}

Este nuevo período se enmarca en la denominada emergencia o reemergencia indígena en América Latina (Bengoa 2000). Como se señaló, se trata de un escenario marcado por una incipiente y limitada política multicultural, cuyo hito mayor es la promulgación de la Ley Indígena, pero donde las cuestiones relativas a la redistribución, la particular situación de pobreza y la marginación política de los pueblos indígenas quedaron mayormente excluidas del debate público.

En vista de ello, las respuestas indígenas no se hicieron esperar. Tales respuestas han sido objeto de análisis y clasificaciones diversas (Foerster y Lavanchy 1999; Lavanchy 2003), sin embargo, para efectos de este artículo, coincidimos con el trabajo de Pairican (2014) en términos de considerar que el grueso del movimiento mapuche de las últimas décadas ha estado caracterizado por dos grandes lineamientos políticos. Uno de ellos, y que es donde se enmarca nuestro análisis, es denominado por el autor como la vía política, representante de una línea más institucional, similar a lo que Burguete (2008) identifica como una estrategia dentro del Estado, aludiendo a organizaciones que, sin salirse de la institucionalidad, actúan en alguno de los espacios de la institucionalidad estatal, disputando el poder al Estado mediante la negociación constante. No se trata de actores indígenas que se conforman con ocupar espacios de gobierno, sino que disputan "real o simbólicamente las instituciones, jurisdicciones y gobiernos locales, que pueden ser, y son, etnizados y significados como propios" (Burguete 2008: 27). En el caso mapuche, estaría representado fundamentalmente por colectivos que han tratado de conquistar los gobiernos locales (Espinoza 2014).

Se trata, sin duda, de una tendencia más amplia en el horizonte regional y mundial. A partir de mediados de la década de 1980, las transformaciones estructurales mencionadas anteriormente afectaron la organización de los países latinoamericanos y marcaron de manera compleja y contradictoria el escenario para la participación y el desarrollo de los actores sociales. Pese a estas dificultades, los vacíos dejados por el Estado abrieron espacios de participación que terminaron por favorecer la construcción de democracias locales y, con ello, la emergencia de nuevos actores políticos (Espinosa 2003). Así, procesos tales como la progresiva importancia que adquirieron los gobiernos locales (Dehouve 2001; Delamaza 2005), la revaloración de lo local como lugar de identidad (Aguilar y Bueno 2003), la reemergencia indígena (Bengoa 2000; Le Bot 2013) y las versiones latinoamericanas del multiculturalismo (Agudelo y Recondo 2007) permitieron configurar un escenario idóneo para que en las últimas décadas numerosos colectivos indígenas se volcaran, a través de la vía electoral, hacia el control de los municipios (Iturralde 1998). Esta forma de acceder a los gobiernos locales se hizo, en muchos casos, a través de movimientos etnopolíticos (Bartolomé 1997) que intentaron la etnización del espacio político municipal (Burguete 2008; Harvey 2008). Se trata de un proceso de reinvención y reafirmación de la identidad étnica que, en paralelo, ejerció acciones políticas activamente construidas para visibilizarse como indígenas y reclamar derechos o establecer políticas en función de dicho reconocimiento (Restrepo 2001; Hoffmann y Rodríguez 2007). En el fondo se observó el anhelo por trascender el simple cambio formal en la distribución del poder político municipal para intentar que los gobiernos locales en manos indígenas tuvieran un sello propio (Ospina 2006).

En Chile, este escenario fue aprovechado, entre otros, por algunos sectores de la sociedad mapuche, los que vislumbraron la posibilidad de capturar esa cuota de poder y utilizarla para potenciarse como pueblo (Foerster y Vergara 2001). Si ya desde mediados del siglo XX es posible observar una base política mapuche que miró hacia su posicionamiento en los gobiernos locales, luego de terminada la dictadura y en los albores de la transición a la democracia, se observa una nueva orientación política mapuche que identifica a los municipios como uno de los ejes estratégicos hacia donde el movimiento mapuche debía orientar su accionar político (Marimán 1990).

Esto se plasmó prontamente en las elecciones de 1992, donde un número significativo de candidatos mapuches se presentaron a las elecciones municipales. En los años siguientes, y en paralelo a un nuevo movimiento étnico mapuche desarrollado a nivel comunal y regional (Durston 2007) que, en algunos casos, transformó al gobierno comunal en un escenario de disputa política (Cayuqueo 2006), no tan solo se vio aumentar el número de candidatos a los cargos municipales de elección popular, sino también puso en evidencia una transformación en la distri- 
bución del poder político municipal. En 1992 hubo cuatro alcaldes y 48 concejales mapuches; durante las elecciones municipales posteriores (1996, 2000, 2004 y 2008) el número fue aumentando, confirmándose dicha tendencia en las últimas elecciones (2012), donde resultaron elegidos 13 alcaldes y 109 concejales mapuches (servel.cl).

Existen, por cierto, matices y en ocasiones diferencias considerables entre estos alcaldes. No es que todos ellos respondan a movimientos etnopolíticos; de hecho, algunos ni siquiera incorporan planteamientos de tipo étnico en sus respectivos despliegues políticos, no obstante, la mayoría sí lo hace. Además, y de manera interesante, muchos de estos alcaldes reconocen como modelo de alcaldía en manos mapuches al gobierno del alcalde de Tirúa, Adolfo Millabur, quien desde 1992 contribuyó de manera protagónica y significativa al desarrollo de un proceso político inédito en la historia de Chile (Espinoza 2011). Se trata del caso paradigmático de un movimiento etnopolítico que buscó controlar el poder municipal, para desde allí introducir transformaciones afines a las demandas y a las reivindicaciones mapuches.

En este sentido, es importante señalar que a pesar del limitado alcance de la descentralización chilena (Delamaza 2005), este tipo de movimientos etnopolíticos ha logrado impactar en los escenarios políticos locales, no tan solo a partir de los cambios observados en la distribución del poder político comunal, sino que, junto a ellos y mutuamente implicados, es posible observar cambios profundos en los niveles infracomunales. Se aprecia un interesante proceso de etnización de la política local y microlocal. Al introducir los alcaldes mapuches una impronta étnica en los municipios, han contribuido a la generación de una cadena de transformaciones que tienen como vector común el desplazamiento de la política desde el lugar formal del municipio, en la cabecera de la comuna, hacia las comunidades, abriendo con ello el lugar de lo político a nuevos actores. Y al producirse esto, al abrirse la posibilidad de inserción de nuevos actores políticos, éstos entran con todos sus dispositivos culturales, produciéndose con ello un proceso complementario de politización de la cultura y culturización de la política (Boccara 2004).

En las últimas décadas se ha observado cómo en comunas que han tenido sucesivos gobiernos de alcal- des mapuches han aflorado una serie de elementos que dan cuenta de esta disputa por la igualdad de lo mapuche en relación con el Estado nacional. Hemos sido testigos de la oficialización del idioma mapuche, el mapudungun, en la comuna de Galvarino, proceso encabezado tanto por el alcalde Huaquil y los concejales mapuches del municipio, como por la organización Consejo Territorial Mapuche de Galvarino. En la vecina comuna de Cholchol se ha visto emerger una gran cantidad de machis, todas ellas cumpliendo un rol relevante en los sistemas de salud intercultural y actividades ceremoniales desarrolladas en la comuna. Hacia la costa, en la comuna de Puerto Saavedra, ha ocurrido algo similar en torno a la salud intercultural, destacándose la presencia de lonkos que, aunque objeto de cierta crítica por algunos sectores dirigenciales e intelectuales mapuches de la comuna, en la última década han incrementado notablemente su número. De hecho, se atribuye al alcalde mapuche Ricardo Tripainao (2004-2012) la promoción de una generación completa de lonkos como representantes y mediadores entre la municipalidad y los distintos territorios infracomunales de la comuna.

Otros procesos cruzan transversalmente este tipo de comunas, por ejemplo, una serie de reconfiguraciones territoriales promovidas por las autoridades municipales mapuches, las que a la par de buscar mayor eficiencia en la implementación de los programas públicos mediante la participación activa y relevante de los territorios infracomunales, han buscado recomponer o reinventar antiguas alianzas territoriales mapuches y empoderar dichos territorios con el objeto de posicionarlos, bajo una lógica supuestamente mapuche, como protagonistas de las dinámicas políticas locales. También se ha observado en el espacio público de estas comunas una abundante presencia iconográfica mapuche: modificaciones en los escudos municipales, en las fachadas y diseños de los edificios municipales, presencia de esculturas y banderas indígenas se suman a cambios en algunos nombres de calles y plazas, sacando o intentando desplazar los nombres de conquistadores españoles o militares chilenos por héroes mapuches. Un caso particularmente interesante es lo ocurrido en Coyhaique, una comuna bastante alejada del territorio histórico mapuche, pero que en la actualidad posee una presencia de personas mapuches cercana al 20\% (Casen 2009; Pladeco 2014-2018), y que 
desde 2012 cuenta con un alcalde mapuche. Este alcalde, Alejandro Huala Canuman, en una de sus primeras medidas, puso una bandera mapuche al lado de la bandera chilena que flamea, como en todo el país, en el frontis del edificio municipal.

Estas y otras transformaciones ocurridas al interior de las comunas con alcaldes mapuches han contribuido de manera importante a fortalecer la identidad mapuche (Caniguan 2007; Montero 2007; Norero 2007). Esto debido a que tales cambios se anclan en cuestiones más profundas, en el posicionamiento de proyectos políticos alternativos y significativos en el nivel local (Espinoza 2014). Aunque en ningún caso se trata de proyectos que permanecen al margen de las dinámicas políticas nacionales, poseen aristas con densidad política propia. Son proyectos que resultan incomprensibles sin tomar en consideración los factores que los engloban. De hecho, se constituyen en buena medida por ellos, pero, así mismo, constituyen experiencias que llevan fuertemente el sello de las dinámicas locales $y$, sobre todo, son proyectos pensados como propios por los actores locales.

Es posible afirmar que esta percepción tiene un correlato empírico en las dinámicas electorales municipales, pues, al contrario de las tendencias electorales nacionales, donde se constata una progresiva y permanente baja en la participación ciudadana (Saldaña 2009; Cantillana 2009), en estas comunas la tendencia es exactamente la contraria. La sucesión de cada elección muestra un aumento en el número de electores..$^{10}$ Esta tendencia electoral, opuesta al resto de las comunas del país, ocurre porque el espacio municipal se ha constituido en un campo de disputa que provoca la confluencia de dinámicas políticas con una densidad política particular. Los actores locales se han volcado hacia las elecciones municipales porque, a diferencia de lo que ha ocurrido en el resto del país donde los electores han debido pronunciarse por cuestiones mínimas, generalmente consensuadas (Moulian 2002), en estas comunas las elecciones pueden poner en juego cuestiones mucho más relevantes en torno a

10 Las comunas en que hemos hecho el seguimiento en la participación electoral y que muestran con claridad este aumento constante son Alto Biobío, Los Álamos y Tirúa en la octava región, y Cholchol, Curarrehue, Galvarino, Lumaco, Pucón, Puerto Saavedra y Renaico en la novena región. temáticas como la igualdad, la distribución de recursos y la protección de las comunidades ante la intervención de agentes estatales $\mathrm{y} / \mathrm{o}$ privados.

\section{* Voces de la etnogénesis. Pueblos indígenas EN LA DISPUTA POR EL RECONOCIMIENTO}

Cuando hablamos de disputas por la igualdad o igualdades, tal como venimos señalando, no solo nos referimos a aspectos relacionados con temas de ocupación e ingreso, como ha sido tradicionalmente comprendido este concepto. Siguiendo a Fraser (2006), un elemento sumamente relevante en las políticas de la igualdad hoy tiene que ver con el reconocimiento y/o visibilización de diferencias que impactan en la distribución de recursos socialmente valorados, en el marco de una sociedad con individuos heterogéneos. Desde esta óptica, la disputa de los pueblos indígenas por la igualdad ha tenido como un punto central la obtención de reconocimiento a ciertas especificidades o trayectorias compartidas que los hacen parte de relaciones históricamente asimétricas. Por esta razón, otra de las vías que abarcaremos en el marco de este artículo la hemos denominado la vía etnogenética en la disputa por la igualdad y se relaciona con todos aquellos procesos culturales que se han transformado desde la década de 1990 en una de las principales expresiones identitarias de los pueblos indígenas en Chile.

Luego de la aparición de los indígenas urbanos como fenómeno emergente después del Censo de 1992, han sido varios los pueblos, comunidades y personas que han optado por autoidentificarse como indígenas, situación que, hasta esa fecha, no ocurría. En el año 1980, según Rupailaf (2002), existían en el ámbito urbano metropolitano de Santiago solo dos organizaciones, Newen Mapu y Admapu, ambas vinculadas además a sectores políticos específicos, la Democracia Cristiana y el Partido Comunista. Quince años después, en un catastro realizado por el Núcleo de Estudios Étnicos y Multiculturales de la Universidad Academia de Humanismo Cristiano, se pudo constatar la existencia de más de 100 organizaciones indígenas en la región Metropolitana (Campos 2008). La verdad es que ya desde la década de 1990 , luego de la inclusión de coyas y likanantay en la Ley 19.253, se dejó abierta la puerta para la aparición de nuevas y viejas identidades, lo que se ha venido confirmando con el paso de los años: quechuas en Mamiña en 1998, ayma- 
ras en Quillagua en 2003, diaguitas en Alto del Carmen en 2006 y hoy solicitud de reconocimiento por parte de changos y de afrodescendientes.11 También se habla de familias y comunidades diaguitas en el Aconcagua, Huasco Bajo y Salamanca, y reetnificación en Chiloé (Yáñez 2012) y la sorprendente revitalización de yámanas y kawésqar, hoy constituidos en comunidades con centenas de miembros.

¿Qué ha sucedido en Chile que permite el resurgimiento, la reaparición de tantos pueblos indígenas que se estimaban desaparecidos? ¿Hay en estos movimientos una abierta manipulación de la identidad con la finalidad de conseguir ciertas modificaciones en el plano distributivo? ¿Es la etnogénesis una vía posible para la superación de las históricas desigualdades generadas en el colonialismo y en la relación con los Estados-naciones?

La etnogénesis se refiere a la reaparición y emergencia de pueblos indígenas que se consideraban hasta entonces como desaparecidos. Algunos autores han diferenciado este término de otros similares como reetnificación, etnificación y revitalización cultural, dependiendo del grado de influencia que puede tener en el movimiento el Estado u otros agentes externos, o del peso del pasado "real" en los procesos identitarios actuales (Eriksen 1993). En este artículo se retoma el concepto de etnogénesis aplicado a un amplio campo de fenómenos culturales que van desde las transformaciones de larga duración, como las planteadas por Boccara (1999), en que una identidad va lentamente fraguándose en la medida en que se contrasta con otras identidades (Cardoso de Oliveira 2007), hasta las que se refieren de manera crítica a la aparición de determinados pueblos indígenas y las consecuencias de su etnificación por parte del Estado (Vázquez 1992) o a los mismos usos políticos de la identidad (Isla 2002). ${ }^{12}$

Desde este enfoque, es posible comprender los procesos

$11 \mathrm{Al}$ respecto véase el Acta de Acuerdos, Consulta Previa, Proyecto que crea el Ministerio de Cultura (2015).

12 Otros autores han puesto énfasis en el carácter instrumental y a veces antojadizo de algunos procesos etnogenéticos, poniendo énfasis en los movimientos "new age" o en la etnicidad como una nueva religión (Galinier y Molinié 2013), mientras que otros han insistido en la línea de la identidad instrumental a partir del estudio de lo étnico en términos comerciales, destacando las relaciones entre cultura, capitalismo e identidad (Comaroff y Comaroff 2011). etnogenéticos actuales como tributarios de varias de las transformaciones sociales tanto nacionales como internacionales observadas a partir de la década de 1980 y ya mencionadas en el primer apartado. La primera de ellas dice relación con los procesos democráticos que afectaron a las repúblicas latinoamericanas a partir de la década de 1980 y que implicaron no solo demandas de tipo político, sino también un aumento de las postergadas presiones redistributivas. En este sentido, los pueblos indígenas se sumaron a las transformaciones políticas hacia gobiernos democráticos, esperando no solo el reconocimiento y mayores cuotas de participación, sino también mejoras en su calidad de vida. En ese escenario muchos migrantes a las ciudades y participantes de movimientos campesinos $\mathrm{y}$ de sindicatos rurales comenzaron un lento proceso de reconsideración identitaria, abriéndose a la posibilidad de la indigenidad o la negridad (Restrepo 2013) como una manera de modificar su posición en el marco de relaciones asimétricas de carácter histórico. Este fenómeno no ha estado restringido a Chile y se viene apreciando desde muchos años atrás en lugares tan distintos como Uruguay, Argentina, México y Colombia con afrodescendientes (Walker 2012), en indios del nordeste en el Brasil (Pacheco de Oliveira 2010), o en México (Bartolomé 2006) o Argentina (Isla 2002; Escolar 2007).

\section{Entre la cultura originaria y los derechos ancestrales}

Los procesos de etnogénesis tienen relación con las condiciones de reconocimiento de lo étnico a nivel mundial, que se ven reflejadas en las distintas disposiciones internacionales relativas a los derechos de los pueblos indígenas (Stavenhagen 1998), pero sobre todo en el reconocimiento y la valoración de la diferencia cultural. Este marco apunta directamente a una crítica a las formas eurocéntricas que se levantaban como el sustento de relaciones desiguales basadas en el componente indígena (Quijano 1993) y que dieron lugar a dos formas diferentes de respuesta desde los pueblos indígenas: la primera tiene relación con la apelación a los derechos diferenciales, en donde la cuestión de la originalidad en su carácter legal toma gran importancia, mientras que la segunda se refiere a la idea de la valoración de las culturas diferentes como una manera de acceder al reconocimiento. Ambas alternativas tienen que ver con estas modificaciones a nivel internacional y han convivido en las diversas formas 
de reconocimiento cultural hacia los pueblos indígenas, si bien el mayor peso que ha tomado cada una de ellas implica diferentes formas de concebir y de pensar lo indígena en nuestros países. La opción por los derechos tiene una vertiente más política, mientras que aquélla por la cultura apela a un imaginario de los indígenas que muchas veces se relaciona con las mismas impresiones que desde el colonialismo se tenía con respecto a los pueblos indígenas, direccionándose hacia el folclor y otras iniciativas como el turismo y la promoción de prácticas de salud complementarias. Resulta interesante que para muchos de los Estados, el reconocimiento de los temas culturales se ha pensado como separado de las cuestiones políticas y de derechos, lo que plantea una comprensión de la diferencia cultural mucho más cercana al multiculturalismo en su mirada anglosajona, ampliamente criticada tanto por líderes indígenas como por intelectuales (Vázquez 2010).

Los procesos etnogenéticos han surgido en los contextos antes señalados, implicando nuevas maneras de evaluar la diferencia cultural, que evidentemente han redundado en nuevas y más amplias formas de reconocimiento. Las modificaciones en las preguntas censales fueron un ejemplo de cómo ciertos cambios en la mirada del Estado hacia los pueblos indígenas tuvieron incidencia directa en el movimiento y en la visibilización de segmentos y procesos que antes eran desconocidos para la mayoría de la población y también para el mundo académico. Es el caso del impacto que tuvieron en Chile los resultados del Censo 1992 con respecto a la población indígena urbana, y que contribuyeron a la aparición, en esos momentos sorpresiva, no solo de una gran cantidad de indígenas, sino también un desafío a las concepciones de indígenas y no indígenas relativas a lo que deberían ser los pueblos originarios en contraste con los imaginarios más difundidos sobre ellos. Esta misma visión con respecto al censo la tienen los afrodescendientes en la actualidad, que han puesto en valor tanto la ejecución de un estudio específico de población realizado por el INE como la demanda por ser incorporados en los futuros censos de población a partir de una pregunta de pertenencia afrodescendiente cuyos resultados se espera puedan apoyar su proceso reivindicativo y su reconocimiento.

Otro caso que apunta a la superación de las desigualdades estructurales de nuestra sociedad es visible en procesos etnogenéticos que surgen como respuesta a las presiones ejercidas por grandes empresas. Estos ejemplos se refieren a determinadas poblaciones que ven en el "convertirse" en indígenas una alternativa eficiente para enfrentar problemas derivados de su relación con esas empresas, tales como la contaminación, la pérdida de tierras o de recursos hídricos, como veremos en el siguiente apartado. De esta manera, la nueva condición originaria permite igualar las condiciones del diálogo colocando nuevas trabas al avance de las empresas, las que al estar enfrentándose a indígenas deben considerar nuevos resguardos y condiciones para la implementación de sus proyectos.

Otro importante proceso de superación de las desigualdades se da en torno a la posibilidad de acceder a ciertas políticas públicas específicas a partir de las nuevas identidades. Esto ha sido evidente en la solicitud de becas indígenas por parte de una gran cantidad de indígenas urbanos en la ciudad de Santiago, más allá de si participan o no en organizaciones étnicamente diferenciadas. En este caso, al contrario de lo que se podría pensar cuando se hace referencia a una identidad instrumental, de carácter capitalista y empresarial (Comaroff y Comaroff 2011), no se hace necesario constituir una identidad instrumentalizada expresada en la visibilización y exacerbación de elementos culturales supuestamente originarios, sino que a lo que se apela es a la condición de sujeto indígena derivada de derechos específicos contemplados, en este caso, en la Ley 19.253 y en las normativas del Ministerio de Educación y de la CONADI. Esto mismo se replica en otras políticas en las que también la pertenencia a un pueblo originario ha implicado determinados beneficios habitacionales, acceso diferenciado a la salud, apoyo productivo y capacitación, todos ellos derivados de los distintos fondos que ha implementado el Estado como una manera de poder pagar la deuda histórica que se tiene con los pueblos indígenas.

En general, lo anterior forma parte del acceso a beneficios específicos que les permiten a los indígenas diferenciarse de los otros ciudadanos de sus países a partir de su nueva condición. En un mundo en donde predominan las políticas neoliberales, el acceso a beneficios como producto de una condición social específica, sustentada en el reconocimiento de ciertos derechos colectivos originarios, los diferencia de los otros pobres de la sociedad y les permite mejorar sin duda su calidad de vida. En esto se incluyen 
obviamente todas las políticas de acción afirmativa o discriminación positiva que en la actualidad se aplican a los indígenas y que sin duda son un campo de motivación para que personas que no se consideraban como tales pasen a considerarse y ser consideradas así. Esto se sustenta en la deuda que existe para con los pueblos indígenas, derivada de las usurpaciones territoriales y la persecución cultural a las que fueron sometidos desde los tiempos coloniales, pero sobre todo luego de la constitución de los Estados-naciones modernos.

Cabe destacar, por último, la cuestión de la negación y la legitimidad que el Estado ha otorgado a estos movimientos, marcada por la posición de histórica desigualdad en la que se encuentra la población indígena. Cuando se analizan los procesos de etnogénesis, generalmente se pone el foco en la supuesta "falsedad" de los movimientos y en la escasa justificación para dar el paso de ser campesinos o proletarios urbanos a ser indígenas, en el campo o en la ciudad. Pero no se debe dejar de lado que en gran parte del siglo XX, bajo criterios de exclusión, asimilación e imposición cultural, se obligó a los indígenas a renegar de sus identidades, como también se tendió a invisibilizar su existencia como parte del encubrimiento de las atrocidades cometidas en los procesos de consolidación nacional. De la misma manera, los procesos de migración forzosa provocaron en los desplazados la pérdida de sus referentes culturales originales, que carecían de sentido al ser accionados en las nuevas condiciones de vida, lo cual no significaba que no estuvieran presentes en muchos de los migrantes. De esta forma, si en condiciones de verdaderas persecuciones culturales los indígenas responden con la invisibilidad y el ocultamiento, ante las nuevas formas de reconocimiento no es extraño que planteen como posible la visibilización de sus formas identitarias, antes ocultas, como una forma estratégica de enfrentarse a las nuevas condiciones de vida. En este sentido, se sigue cuestionando el que se retomen las identidades y se utilicen con fines instrumentales, lo que no debería extrañar, ya que si hace algunos años ser portador de una condición distintiva como la indígena era sinónimo de persecución y estigma, en la actualidad lentamente se va transformando en símil de derechos específicos, los que en muchos casos están siendo activados. Y ésa es en definitiva la principal causa de la reaparición de estos nuevos/viejos indios.

\section{* Voces desde lo sociomedioambiental. Pueblos indígenas en la disputa por los RECURSOS NATURALES}

Otro de los campos en los que es posible ver los avances y las estrategias de los pueblos indígenas es en la disputa por el acceso a y por la propiedad de los recursos naturales, así como en torno a la gestión de externalidades negativas de la economía. Estos elementos han sido particularmente importantes en las últimas décadas, en el marco de un renovado interés extractivo en nuestro país, tributario de las transformaciones económicas detalladas en el primer apartado. Este ítem está estrechamente relacionado con el revisado con anterioridad, ya que muchas veces se encuentra en la base de ciertos procesos etnogéneticos en el marco de los conflictos emergentes de estas dinámicas económicas.

La reorientación de la economía chilena a partir de la década de 1980 aumentó la presión por la explotación intensiva de recursos estratégicos exportables, muchos de ellos ubicados en territorios indígenas. Esto ha implicado la importante expansión de industrias altamente costosas ambientalmente en estos territorios y de concentraciones urbanas asociadas, con el consiguiente perjuicio para las economías locales indígenas, ya bastante deterioradas. Estos hechos han ido en directo desmedro de la situación de los pueblos indígenas y han puesto en evidencia que cuando hablamos de desigualdad, no solo debemos detenernos en las variables clásicas como ingreso u ocupación. Al igual que otros bienes socialmente valorados, en sociedades desiguales como la chilena el vivir en un ambiente no degradado es también un bien que encuentra una distribución desigual: las variables que influyen de manera más decidida a que los sujetos se vean expuestos a vivir en un territorio degradado ambientalmente son las mismas que determinan su acceso a otros bienes, tales como el ingreso, el estatus, la clase y el género. En el caso latinoamericano, además, la pertenencia a pueblos indígenas o afrodescendientes ocupa también un lugar particularmente relevante (Espinoza y Rabi 2013).

Este fenómeno ha sido profusamente analizado y documentado por quienes han trabajado con los conceptos de racismo ambiental y justicia ambiental a partir de la década de 1970 (Bullard 1999; Dosbon 1998; Checker 2005) 
y ha sido señalado también para el caso latinoamericano en la última década (Guimarães 2012; Auyero y Swistún 2008; Vázquez y Salgado 2009, Göbel et al. 2014). En el caso chileno, esto resulta notorio si analizamos la composición poblacional en términos socioeconómicos, en las que se concentran algunas de las actividades económicas más costosas ambientalmente: las comunas con mayor porcentaje de población indígena en Chile son las que muestran los peores indicadores en términos de pobreza, ingreso y niveles educacionales, concentrando a su vez los conflictos socioambientales de mayor relevancia y persistencia en las últimas décadas. Casos paradigmáticos sobre este tema son el histórico conflicto territorial de la novena región entre mapuches, Estado, colonos e industria forestal por las tierras cultivables y el escenario contencioso entre comunidades indígenas atacameñas, Estado y minería por los derechos de agua en el desierto de Atacama. Ambos son conflictos de larga data, que han precarizado aún más la situación ya vulnerable de los pueblos indígenas, aumentando los niveles de pobreza y el desplazamiento desde sus territorios. Hoy en día una buena parte de las industrias con altos costos ambientales o externalidades negativas de la expansión urbana, se encuentran emplazadas sobre o aledañas a tierras comunitarias o con reclamos territoriales de pueblos indígenas vigentes: los rellenos de residuos sólidos, plantas de tratamiento de aguas servidas, la mediana y gran minería metálica, la industria pesquera y salmonera, la industria forestal, por nombrar los focos más relevantes de conflicto en las últimas décadas.

En el marco de estas dinámicas, las comunidades indígenas locales se han visto directamente afectadas por actividades altamente costosas en términos ambientales y sus formas de subsistencia han resultado gravemente deterioradas. La explotación de recursos ha ocurrido en espacios locales, pero sus beneficios han sido trasladados hacia áreas metropolitanas a través de mecanismos como la tributación y los impuestos (Bebbington y Bebbington 2009). Estos patrones persistentes de relación asimétrica entre Estado y pueblos indígenas implican que este tipo de poblaciones hayan debido asumir el costo de las transformaciones socioambientales que han deteriorado sus formas de vida, pero sin poder disfrutar de los beneficios que generan a nivel nacional (Martínez-Alier 2002, 2004, 2009). Los efectos de la degradación ambiental ocasionada por la concentración de estas actividades se ven agravados en los casos en que hay gran cantidad de población indígena, pues constituyen un elemento más dentro de un contexto de vulnerabilidad que dificulta los procesos de acción/reacción/protección de las comunidades. En ese sentido, parte importante de la disputa por la igualdad que han emprendido los pueblos indígenas frente al Estado o actores privados en la defensa de sus recursos y territorios, ha implicado un complejo proceso previo a través del cual han ido elaborando, no sin dificultades, un repertorio de acciones protectoras muchas veces inexistentes.

Dentro de estos procesos de larga data, diversos sectores al interior del movimiento indígena se han visto involucrados, a partir de la década de 1990, en debates tan relevantes como los tipos y vías de desarrollo, la distribución económica de beneficios y costos de las actividades económicas y el manejo de recursos estratégicos. Los recientes conflictos socioambientales que han involucrado a los pueblos indígenas, han puesto en el tapete cuestiones fundamentales relativas al lugar de estos pueblos en el proyecto nacional a futuro, abriendo también un debate al interior de las comunidades sobre la necesidad de discutir temas como la sustentabilidad de sus economías, sus proyecciones a futuro como pueblos y la necesidad de revertir situaciones históricas de exclusión en torno al manejo de recursos contenidos en su territorio.

Como resultado de esto y en términos generales, es posible decir que se han logrado articular de manera bastante exitosa tres tipos de herramientas, ancladas en lo que hemos llamado para efectos de este artículo intersticios del régimen de desigualdad. En primer lugar, han considerado temas jurídicos vinculados a la Ley Indígena en torno a la recuperación o reclamo de tierras en territorio ancestral, propiedad de derechos de agua, borde costero y subsuelo. En esta línea, la legislación indígena ha apuntalado procesos conflictivos ya puestos en marcha por parte de sus actores, así como, en algunos casos, se ha constituido en el único recurso de protección de algunas comunidades frente a amenazas ambientales de amplio impacto para sus economías. Como veíamos anteriormente, las promesas de la Ley Indígena y el rol de la CONADI en la recuperación de territorios, derechos de agua, borde costero y subsuelo si bien no han tenido el efecto redistributivo esperado, han logrado revertir situaciones críticas al respecto. Un ejemplo de esto es el ya mencionado jui- 
cio favorable a las comunidades por los derechos de agua de la comunidad atacameña de Toconce en 2004,13 que permitió zanjar un problema de larga data en un contexto particularmente delicado en términos de disponibilidad del recurso hídrico. Otro ejemplo de esto fue la restitución parcial de derechos de agua a la comunidad indígena de Chiu Chiu, a través de la gestión de la CONADI, que tenía gravemente afectada la producción agrícola desde la promulgación del Código de Aguas, cuando fueron enajenados a través de un proceso irregular de inscripción de derechos. En estos casos, así como en otros igualmente conocidos, como el del pueblo de Quillagua, los conflictos socioambientales que se han desatado en sus territorios han activado importantes procesos de etnogénesis al incorporar la Ley Indígena al repertorio de acciones protectoras posibles en un contexto de vulnerabilidad.

Así, aun en los casos en que la acción a través de la Ley Indígena no ha implicado la recuperación o mayor control sobre los recursos del territorio - dadas sus ya señaladas falencias en el marco del régimen de desigualdad chileno-, los requisitos impuestos por la Ley Indígena para los reclamos han significado importantes avances en la asociatividad e instalado en las comunidades el diagnóstico de que existe un problema y la necesidad de realizar acciones dirigidas a resolverlo de manera colectiva, situación que ha gatillado diversas reacciones y estrategias mixtas al interior del movimiento indígena, ya sea desde la política institucional, la protesta o la judicialización de los conflictos. Es el caso, por ejemplo, de las comunidades mapuches de Tromen y Boyeco (novena región) en la disputa por el cierre del vertedero emplazado en territorios pertenecientes a las comunidades. Tras un largo y complejo proceso en la construcción de asociatividad en el marco de la Ley Indígena, algunas de las comunidades más afectadas han decidido emprender acciones judiciales (2015) a partir de estas asociaciones, en busca de reparación por el daño causado tanto a la economía doméstica y el valor del suelo como a sus formas de vida tradicional. En ese sentido, observamos un intento concreto por disputar des-

13 Este fallo tiene fecha del 22.04.2004. En esa ocasión, el Segundo Juzgado de Letras de El Loa Calama, mediante sentencia de primer grado declaró que la demandante Comunidad Atacameña de Toconce es dueña del derecho de aprovechamiento de aguas superficiales y corrientes, de uso consuntivo y de ejercicio permanente y continuo, en el río Toconce en contra de la empresa Essan S.A. de los sujetos condiciones para una mayor igualdad. Así, también, frente a la creciente presión extractiva, hoy la Ley Indígena y las comunidades legalmente reconocidas y protegidas por ésta, se han constituido en una herramienta más en función de negociar condiciones favorables en el marco de la instalación de nuevos proyectos o evitar en alguna medida nuevos escenarios de victimización, que podrían agravar la relación de desigualdad antes descrita. Cabe señalar, sin embargo, que la posición histórica de los pueblos indígenas en el marco del Estado nacional no permite sacar cuentas alegres respecto de este tema, pese a los avances alcanzados por las comunidades en esta línea, pues muchas veces estas negociaciones se realizan en marcos asimétricos que van a la larga generando fragmentación y relaciones clientelares fomentadas por el Estado o agentes privados.

En segundo lugar, otra herramienta en esta disputa por la igualdad por parte de los pueblos indígenas ha sido la legislación ambiental y los recursos, la información y las redes que los organismos medioambientales han podido aportar en el marco de los conflictos que involucran territorios indígenas. En este punto resulta relevante la creciente resonancia que el discurso en torno a problemáticas de esta línea ha ido adquiriendo en nuestro país y en el mundo en las últimas décadas, fenómeno que ha producido cierta coincidencia entre movimiento indígena, movimiento medioambiental y movimientos de protesta por la distribución de costos del modelo extractivista en América Latina. En el caso de nuestro país, han resultado claves las asesorías y la difusión de los conflictos que involucran a los pueblos indígenas de organizaciones como Terram, Océana, OLCA, entre otras. Junto con fomentar la asociatividad y las estrategias protectoras de estas comunidades, han actuado como cajas de resonancia de problemáticas que por los niveles de visibilidad pública desigual han pasado inadvertidas por largo tiempo. Un caso emblemático de este fenómeno, aunque con resultados adversos, fue la coyuntura específica de la construcción de la represa Ralco (1999) en territorios mapuches, que logró hacer confluir organizaciones del mundo indígena y organismos relacionados con temáticas socioambientales en un debate nacional sobre desarrollo. Hoy en día, este fenómeno puede observarse también en el conflicto que mantienen las comunidades diaguitas y la Barrick Gold Corporation por el emblemático proyecto minero en el norte del país (2014). En esta misma línea, 
la legislación ambiental también ha sido utilizada como una herramienta de protección por las comunidades, las que han imputado las resoluciones de calificación ambiental, los estudios de impacto y otros elementos requeridos por la legislación ambiental con el fin de visibilizar aspectos en los que la Ley Indígena no tiene alcance.

En tercer lugar, y finalmente, el reconocimiento del Convenio 169 de la OIT por parte de nuestro país también ha comenzado a ser utilizado como herramienta para aumentar las instancias de visibilidad internacional para las demandas de las comunidades indígenas, aun cuando en términos de medidas reparatorias, precautorias y de sanción no han resultado eficaces. En esos términos, el uso de esta herramienta jurídica si bien no ha tenido efectos directos en la paralización de ciertos proyectos o en términos reparatorios sobre situaciones de degradación consolidada o de expoliación documentada, ha provocado que "al mundo le importe" lo que sucede con los pueblos indígenas, apuntalando los procesos internos de protección y cohesión de las comunidades en varios conflictos recientes.

En esta línea, es posible decir que aun cuando en el actual escenario la presión sobre los territorios indígenas ha aumentado en términos de la explotación de recursos naturales y la localización de externalidades negativas del desarrollo, se observa también un aumento del rol activo de las comunidades locales en el impulso de estrategias protectoras y repertorios de acción en la búsqueda de una mayor igualdad. Si bien esto no ha generado un impacto susceptible de ser observado en los grandes indicadores de desigualdad y pobreza, sin duda representan un avance con efectos positivos en un futuro, tanto en los niveles de asociatividad como en el control territorial y la visibilidad pública. Queda entonces avanzar en el fortalecimiento de estas estrategias, robusteciendo aquellas herramientas que están siendo utilizadas por estos pueblos.

\section{$\diamond$ Conclusiones}

A través de este artículo hemos buscado visibilizar algunas vías en la disputa por la igualdad que han sido utilizadas por sectores al interior de los pueblos indígenas a partir de la década de 1990 . Hemos podido observar cómo, a pesar del escenario lleno de limitaciones y asimetrías históricas, se pueden identificar espacios intersticiales por donde se filtra su acción en la disputa por una condición de mayor igualdad.

A partir de la promulgación de la Ley Indígena se establece un escenario de luces y sombras en el cual los sujetos indígenas deben inscribir su acción: por una parte este aparato jurídico deja en un segundo plano aquellas demandas históricas en el plano redistributivo y económico, pero por la otra, establece una serie de posibilidades de acción que comienzan a ser utilizadas de forma estratégica por estos actores y que van a marcar el pulso del movimiento indígena en nuestro país a partir de ese momento. Esto va en la línea de lo planteado por Wolf (1980 [1966]), quien hace hincapié en la importancia que para la historia de los pueblos tienen aquellas "zonas grises" por las que entran los menos poderosos a modificar aspectos centrales de la configuración de una sociedad.

En ese sentido, resulta relevante observar cómo un ámbito tan estratégico del régimen de desigualdad chileno como es el marco legal del Estado es utilizado para posicionar, reivindicar, defender o incluso para revertir procesos que han afectado históricamente el desarrollo de los pueblos indígenas. Este proceso no se limita a la aplicación de la Ley Indígena, como hemos visto en el apartado anterior, sino que se extiende a la legislación ambiental y al ámbito político electoral, entre otros aspectos centrales para la distribución de recursos socialmente valorados. Estos espacios intersticiales y las formas en que han sido utilizados por los pueblos indígenas en las últimas décadas han ido modificando de manera importante este escenario: en estas materias Chile no es el mismo que el que fue hace ya casi tres décadas.

Las experiencias analizadas nos muestran que parte importante de estos cambios han sido impulsados por los mismos actores indígenas, poniendo con ello en relieve el rescate de la agencia de los sujetos sociales en el marco de las dinámicas de la estructura social. Cuando analizamos situaciones de desigualdad y pobreza persistentes, los estudios de campo muestran una tendencia a invisibilizar el rol de la acción en el marco de las grandes transformaciones estructurales. Sin embargo, los casos analizados nos muestran que si bien estas grandes transformaciones estructurales tienen un impacto directo sobre los sujetos, en términos de que delimitan condiciones de desigualdad histórica o de agudización de la pobreza, los sujetos 
trazan, a partir de estas condiciones, estrategias y vías para modificar su situación.

Las tres vías analizadas nos hablan de este esfuerzo: partiendo de una situación de desigualdad histórica y pobreza aguda, los pueblos indígenas han avanzado en pos de una mayor igualdad. Se plantean hoy la disputa por el poder político a través del control de los gobiernos locales, a la vez que utilizan los intersticios de la Ley Indígena para obtener reconocimiento de su particularidad cultural e histórica. Plantean preguntas sobre su propia identidad mientras disputan activamente aquellos recursos que constituyen la base de su subsistencia. En cada una de las vías analizadas observamos cómo a partir de ciertas condiciones, los sujetos van imaginando escenarios y utilizando las herramientas que tienen a su disposición para hacerlos realidad.

Sin embargo, aún queda mucho por avanzar. Este esfuerzo, si bien ha modificado ciertos aspectos de la relación entre pueblos indígenas y Estados nacionales, no ha logrado destrabar aquellos aspectos sustanciales que han configurado la posición desigual de los primeros. Todavía hay un largo camino en la construcción de -parafraseando a Fraser (2006) - una justicia social para la era de la política de la identidad. Una que vincule la redistribución, el reconocimiento y la participación con el mismo nivel de importancia. Hoy por hoy y pese a estas estrategias, los pueblos indígenas siguen estando en desventaja y hay cuestiones fundamentales del reconocimiento y el territorio que permanecen pendientes y que no pueden esperar. Esto depende de la modificación de la rígida estructura del poder en Chile, cuyo carácter impermeable ha paralizado los avances en esta materia y en otras relativas a grupos vulnerables. Queda hoy pendiente, entonces, abrir un debate sobre estos puntos y establecer condiciones para que estas estrategias analizadas permitan avanzar en los aspectos redistributivos centrales para el mejoramiento de las condiciones de los pueblos indígenas y de nuestra sociedad en su conjunto. 


\section{* Referencias citadas}

ACKER, J. 2006. Inequality Regimes: Gender, Race, and Class in Organizations. Gender \& Society 20(4): 441-464.

ACTA DE ACUERDO. 2015. Consejo Nacional de la Cultura y las Artes, 22 de marzo de 2015, Valparaíso, Chile. http://consultaindigena.cultura.gob.cl/wpcontent/uploads/2015/04/ doco0769520150326165133.pdf

AGOSTINI, C., P. BROWN Y A. ROMÁN. 2010. Estimando indigencia y pobreza indígena a nivel regional con datos censales y encuestas de hogares. Cuadernos de Economía 47 (Mayo): 125-150.

AGUDELO, C. Y D. RECONDO. 2007. Multiculturalismo en América Latina. Del Pacífico mexicano al Pacífico colombiano. En Los retos de la diferencia. Los actores de la multiculturalidad entre México y Colombia, O. Hoffmann y M. T. Rodríguez (Eds.), pp. 57-80. CIESAS, CEMCA, IRD, ICAHN, México.

AGUILAR, E. Y C. BUENO. 2003. La globalización de las expresiones locales. En Las expresiones locales de la globalización: México y España, C. Bueno y E. Aguilar (Coords.), pp. 5-46. CIESAS, Universidad Iberoamericana, México.

ASAD, T. 1992. Conscripts of Western Civilization. En Civilization in Crisis: Anthropological Perspective, vol. 1 de Dialectical Anthropology: Essays in Honour of Stanley Diamond, C. Ward Gailey (Ed.), pp. 333351. University of Florida Press, Gainsville.

ATRIA, R. 2004. Estructura ocupacional, estructura social y clases sociales. Documento de Trabajo. Serie Políticas Sociales 96, pp. 1-51. FLACSO-Chile, Santiago.

AUYERO, J. y D. SWISTUN. 2008. Inflamable. Estudio del sufrimiento ambiental. Paidós, Buenos Aires.

AYLWIN, J. 2001. Pueblo mapuche y municipio: una reflexión desde el derecho. En Municipios: Participación (o exclusión) mapuche, R. Morales (Ed.), pp. 15-30. Instituto de Estudios Indígenas, UFRO, Ediciones Escaparate, Temuco.

AYLWIN, J., M. MEZA-LOPEHANDÍA Y N. YÁÑEZ. 2013. Los pueblos indigenas y el derecho. LOM, Santiago.

BARTOLOMÉ, M. A. 1997. Gente de costumbre y gente de razón: Las identidades étnicas en México. Siglo XXI, México.

BARTOLOMÉ, M. A. 2006. As etnogêneses: Velhos atores e novos papéis no cenário cultural e político. MANA 12(1):39-68.
BAUER, C. 2009. Dams and Markets: Rivers and Electric Power in Chile. Natural Resources Journal 49: 583-651.

Bebbington, A. y D. Humphreys Bebbington. 2009. Actores y ambientalismos: Conflictos socio-ambientales en Perú. Íconos. Revista de Ciencias Sociales 35: 117-128.

BENGOA, J. 1999. Historia de un conflicto. El Estado y los mapuches en el siglo XX. Palenta, Santiago.

BENGOA, J. 2000 [1985]. Historia del pueblo mapuche: siglos XIX XXX. LOM, Santiago.

BENGOA, J. 2000. La emergencia indigena en América Latina. FCE, Santiago.

BENGOA, J. y E. VALENZUELA. 1984. Economía mapuche: pobreza y subsistencia en la comunidad mapuche contemporánea. PAS, Santiago.

BOCCARA, G. 1999. Etnogénesis mapuche: resistencia y restructuración entre los indígenas del centro-sur de Chile (siglos XVIXVIII). Hispanic American Historical Review 79 (3): 425-461.

BOCCARA, G. 2004. Del Buen Gobierno en Territorio Mapuche. Notas acerca de una experiencia en salud complementaria. Cuadernos de Antropología Social 20: 113-129.

BUDDS, J. 2004. Power, Water and Neoliberalism: The Political Ecology of Water in Chile. Singapore Journal of Tropical Geography, 25(3).

BUDDS, J. 2007. Derechos de agua, pobreza y manejo ambiental en Chile: recursos hídricos, minería y pueblos indígenas en el Norte Grande. En Pluralismo legal, reforma hídrica y políticas de reconocimiento, R. Boelens, A. Guevara, J. Hendrix y J. Hoogesteger, pp. 156-173. WALIR Studies 13.

BUDDS, J. 2009. Contested H2O: Science, Policy and Politics in Water Resources Management in Chile. Geoforum 40: 418-430.

BULLARD, R. 1999. Confronting Enviromental Racism. Voices from the Grassroots. South End Press, Cambridge.

BURGUETE, A. 2008. Gobernar en la diversidad en tiempos de multiculturalismo en América Latina. En Gobernar (en) la diversidad: Experiencias indígenas desde América Latina. Hacia la investigación de co-labor, X. Leyva, A. Burguete y S. Speed (Coords.), pp. 15-64. CIESAS, Flacso-Ecuador y Guatemala, México. 
CAMPOS, L. 2002. La problemática indígena en Chile. De las políticas indigenistas a la autonomía cultural. UAHC, Revista de la Academia, 7: 39-58.

CAMPOS, L. 2008. Relaciones interétnicas en pueblos indígenas de México y Chile. Universidad Academia de Humanismo Cristiano, Santiago.

CANIGUAN, N. 2007. Municipio, identidad y alcalde mapuche. Estudio de caso en la comuna de Saavedra. Tesis de Licenciatura (inédita), Universidad Academia de Humanismo Cristiano, Santiago.

CANTILLANA, C. 2009. Inscritos que no votan: la abstención electoral en Chile y sus factores explicativos. En El genoma electoral chileno. Dibujando el mapa genético de las preferencias políticas en Chile, P. Navia y M. Morales (Eds.), pp. 77-96. Ediciones UDP, Santiago.

CARDOSO DE OLIVIERA, R. 2007. Etnicidad y estructura social. CIESAS, UAM, México.

CAYUQUEO, P. 2006. Participación y voto mapuche en las municipales. Recuperado de http://www.nodo50.org/azkintuwe/ mapuches_municipales.pdf

CEPAL. 2012. Pobreza infantil en pueblos indígenas y afrodescendientes de América Latina. Serie Documentos de Proyectos 477. Recuperado de http://repositorio.cepal.org/handle/11362/3981

CHECKER, M. 2005. Polluted Promises. Environmental Racism and the Search for Justice in a Southern Town. New York University Press, Nueva York.

CIMADAMORE, A., R. EVERSOLE y J. A. MCNEISH. 2006. Pobreza y pueblos indígenas. Una introducción a los enfoques multidisciplinarios. En Pueblos indigenas y pobreza. Enfoques multidisciplinarios, A. Cimadamore, R. Eversole y J. A. McNeish (Coords.), pp.17-40. CLACSO, Buenos Aires.

COMAROFF, J. y J. COMAROFF. 2011. Etnicidad S.A. Katz, Madrid.

CONSEJO NACIONAL DE EVALUACIÓN DE LA POLÍTICA DE DESARROLLO SOCIAL (CONEVAL). 2012. La pobreza en la población indígena de México. CONEVAL, México.

COSTA, S. 2015. Asimetrías, diferencias, interdependencias: Regímenes de desigualdad en América Latina. En Desigualdades. Tolerancia, legitimación y conflicto en las sociedades latinoamericanas, $\mathrm{M}$. Castillo y C. Maldonado, pp. 125-149. RIL, Santiago.

CVHYNT. 2008. Informe de la Comisión de Verdad Histórica y Nuevo Trato. Pehuén, Santiago.
DEHOUVE, D. 2001. Ensayo de geopolítica indígena. Los municipios tlapanecos. CIESAS, Miguel Ángel Porrúa, México.

DELAMAZA, G. 2005. Tan lejos tan cerca. Políticas públicas y sociedad civil en Chile. LOM, Santiago.

DOSBON, A. 1998. Justice and the Environment: Conceptions of Environmental Sustainability and Theories of Distributive Justice. Oxford University Press, Nueva York.

DURSTON, J. 2007. Poder local y movimiento étnico en Villarrica, Chile. En Movimientos indigenas y gobiernos locales en América Latina, W. Assies y H. Gundermann (Eds.), pp. 290-327. IIAM, Santiago.

ERIKSEN, T. H. 1993. Ethnicity and Nationalism: Anthropological Perspectives. Pluto Press, Londres.

ESCOLAR, D. 2007. Dones étnicos de la Nación. Identidades huarpe y modos de producción de soberanía en Argentina. Prometeo, Buenos Aires.

ESPINOSA, M. F. 2003. Descentralización, poderes locales indígenas y manejo de recursos naturales en el Ecuador. En Gobiernos locales y reforma del Estado en América Latina, W. Assies (Ed.). Colmich, México.

ESPINOZA, C. 2011. Mapuches y poder local. Transformaciones en el escenario político de Tirúa (1992-200o), Chile. Tesis de Doctorado (inédita). CIESAS-D.F., México.

ESPINOZA, C. 2104. Municipio, procesos electorales y etnicidad. Transformaciones en la distribución del poder político municipal. En Pueblos indigenas, Estados nacionales y fronteras. Tensiones y paradojas de los procesos de transición contemporáneos en América Latina, Tomo I, S. Valverde, H. Trinchero y L. Campos (Coords.), pp. 247-298. Facultad de Filosofía y Letras-UBA, Buenos Aires.

ESPINOZA, V. 2006. La movilidad ocupacional en el Cono Sur. Oportunidades y desigualdad social. Revista de Sociología 20 : 131146. Universidad de Chile, Santiago.

ESPINOZA,V. y V. RABI. 2013. La desigualdad social en las relaciones interétnicas en el Chile actual. En Pueblos originarios y sociedad nacional en Chile. La interculturalidad en las prácticas sociales, J. W. Durston (Coord.). Programa Conjunto Fortalecimiento de las Capacidades Nacionales de Prevención de Conflicto Intercultural-PNUD Chile, Santiago.

FILGUEIRA, C. 2000. La actualidad de viejas temáticas: sobre los estudios de clase, estratificación y movilidad social en América Latina. CEPAL, Santiago. 
FRASER, N. 2006. La justicia social en la era de la política de la identidad: redistribución, reconocimiento y participación. En Redistribución y reconocimiento. Un debate político filosófico, N. Fraser y A. Honneth (Eds.), pp. 83-99. Morata, Madrid.

FOERSTER, R. y S. MONTECINO. 1988. Organizaciones, líderes y contiendas mapuches (1900-1970). Centro de Estudios de la Mujer, Santiago.

FOERSTER, R. y J. LAVANCHY. 1999. La problemática mapuche. Sociedad-Política-Economía. Análisis del año 1999: 65-102.

FOERSTER, R. y J. VERGARA. 2001. Algunas transformaciones de la política mapuche en la década de los noventa. Anales de la Universidad de Chile, VI, Serie 13: 2-23.

GALINIER, J. y A. MOLINIÉ. 2013. Los neo-indios. Una religión del tercer milenio. Abya-Yala, Quito.

GÖBEL, B., M. GÓNGORA y A. ULLOA. 2014. Desigualdades socioambientales en América Latina. Iberoamerikanisches Institut, Universidad Nacional de Colombia, Bogotá.

GUIMARÃES, R. 2012. Environment and Socioeconomic Inequalities in Latin America. Notes for a Research Agenda. Working Paper 20, pp. 1-33. DesiguALdades.net Research Network on Interdependent Inequalities in Latin America, Berlín.

HABERMAS, J. 1999. La inclusión del otro. Estudios de teoría política. Paidós, Barcelona.

HARVEY, N. 2008. Gobernar en la diversidad: análisis comparativo. En Gobernar (en) la diversidad: Experiencias indígenas desde América Latina. Hacia la investigación de co-labor, X. Leyva, A. Burguete y S. Speed (Coords.), pp. 525-542. CIESAS, Flacso-Ecuador y Guatemala, México.

HOFFMANN, O. y M. RODRÍGUEZ. 2007. Introducción. En Los retos de la diferencia. Los actores de la multiculturalidad entre México y Colombia, O. Hoffmann y M. T. Rodríguez (Eds.), pp. 13-56. CIESAS, CEMCA, IRD, ICAHN, México.

INE-Orígenes. 2005. Estadísticas Sociales de los Pueblos Indígenas, Censo 2002. http://www.ine.cl/canales/chile_estadistico/estadisticas_sociales_culturales/etnias/pdf/ estadisticas_indigenas_2002_11_09_09.pdf

ISLA, A. 2002. Los usos políticos de la identidad. Indigenismo y Estado. Editorial de las Ciencias, FLACSO, BUENOS AIRES.
ITURRALDE, D. 1998. Movimientos indígenas y contiendas electorales (Ecuador y Bolivia). En Autonomías étnicas y Estados nacionales, M. A. Bartolomé y A. Barabas (Eds.), pp. 231-241. Instituto Nacional de Antropología e Historia (INAH), México.

KYMLICKA, W. 1996. Ciudadanía multicultural. Una teoría liberal de los derechos de las minorías. Paidós, Barcelona.

LAVANCHY, J. 2003. El Pueblo mapuche y la globalización. Apuntes para una propuesta de comprensión de la cuestión mapuche en una era global. Trabajo presentado en el Seminario Desarrollo hacia fuera y globalización en Chile, siglos XIX y XX, dictado por el profesor Gabriel Salazar, Facultad de Filosofía y Humanidades, Universidad de Chile, 2003. Recuperado de http:// www.archivochile.com/Pueblos_originarios/estud/POestudiosooo5.pdf

LE BOT, Y. 2013. La gran revuelta indígena. Universidad Iberoamericana-Puebla, Océano, México.

LEÓN, A. y J. MARTÍNEZ. 2001. La estratificación social chilena hacia fines del siglo XX. Documento de trabajo, Serie Políticas Sociales 52, pp 1-41. CEPAL, ECLAC, Santiago.

MARIMÁN, J., 1990. Cuestión mapuche, descentralización del Estado y autonomía regional. CEDM, LIWEN. Materiales de Discusión 1: 189-205.

MARTÍNEZ-ALIER, J. 2002. The Environmentalism of the Poor: A Study of Ecological Conflicts and Valuation. Edward Elgar, Glosario.

MARTÍNEZ-ALIER, J. 2004. Distribution Conflicts Ecological of Sustainability indicators. International Journal of Political Economy 34(1): 13-30.

MARTÍNEZ-ALIER, J. 2009. Social Metabolism, Ecological Distribution Conflicts, and Languages of Valuation. Capitalism $\mathrm{Na}$ ture Socialism 20(1): 58-87.

MARTÍNEZ, J. y E. TIRONI. 1985. Las clases sociales en Chile. Cambio y estratificación, 1970-1980. Colección Estudios Sociales, SUR, Santiago.

MELLA, M. 2001. Movimiento mapuche en Chile: 1977-2000. Tesis de Licenciatura (inédita). Universidad Academia de Humanismo Cristiano, Santiago.

MONTERO, H. 2007. Identidad étnica y municipio. La nueva comuna de Chol Chol dirigida por un alcalde mapuche. Tesis de Licenciatura (inédita). Universidad Academia de Humanismo Cristiano, Santiago. 
MOULIAN, T. 2002. El sistema de partidos en Chile. En El asedio a la política. Los partidos latinoamericanos en la era neoliberal, M. Cavarozzi y J. M. Abal (Comps.), pp. 241-257. Homo Sapiens, Buenos Aires.

NORERO, R. 2007. Municipio y etnicidad: El caso de la comuna de Alto Biobío. Tesis de Licenciatura (inédita). Universidad Academia de Humanismo Cristiano, Chile.

OSPINA, P. 2006. Movimiento indígena ecuatoriano, gobierno territorial local y desarrollo económico: los casos del Gobierno Municipal de Cotacachi y el Gobierno Provincial de Cotopaxi. En En las fisuras del poder. Movimiento indígena, cambio social y gobiernos locales, P. Ospina (Coord.), pp. 15-118. Instituto de Estudios Ecuatorianos, Quito.

PAIRICAN, F. 2014. Malon. La rebelión del movimiento mapuche 19902013. Pehuén, Santiago.

PACHECO DE OLIVEIRA, J. 2010. ¿Una etnología de los indios misturados? Identidades étnicas y territorialización en el Nordeste de Brasil. Desacatos 33, mayo-agosto: 13-32.

PORTES, A. y N. HOFFMAN. 2003. Las estructuras de clase en América Latina: composición y cambios durante la época neoliberal. Serie políticas sociales 68. CEPAL.

PRIETO, M. y C. BAUER. 2012. Hydroelectric Power Generation in Chile: An Institutional Critique of the Neutrality of Market Mechanisms. Water International 37(2): 131-146

QUIJANO, A. 1993. Colonialidad del poder, eurocentrismo y América Latina. En La colonialidad del saber: eurocentrismo y ciencias sociales. Perspectivas latinoamericanas, E. Lander (Comp.), pp. 201246. CLACSO, Buenos Aires.

RESTREPO, E. 2001. Imaginando comunidad negra: etnografía de la etnización de las poblaciones negras del Pacífico Sur colombiano. En Acción colectiva, Estado y etnicidad en el Pacífico colombiano, M. Pardo (Ed.), pp. 41-70. Instituto Colombiano de Antropología e Historia, Bogotá.

RESTREPO, E. 2013. Etnitización de la negridad. La invención de las 'comunidades negras' como grupo étnico en Colombia. Universidad del Cauca, Popayán.

RUPAILAF, R. 2002. Las organizaciones mapuches y las políticas indigenistas del Estado chileno (1970-2000). UAHC. Revista de la Academia 7: 59-103.
SALDAÑA, J. 2009. Crisis en la participación electoral y debate sobre la obligatoriedad del voto en Chile. En El genoma electoral chileno. Dibujando el mapa genético de las preferencias políticas en Chile, P. Navia y M. Morales (Eds.), pp. 55-76. Universidad Diego Portales, Santiago.

STAVENHAGEN, R. 1998. El sistema internacional de los pueblos indígenas. En Autonomías étnicas y Estados nacionales, M. A. Bartolomé y A. Barabas (Eds.), pp. 49-72. INAH, Conaculta, México.

TAYLOR, C. 1993. El multiculturalismo y la política del reconocimiento. FCE, México.

TORCHE, F. y G. WORMALD. 2007. Chile, entre la adscripción y el logro. En Estratificación y movilidad social en América Latina. Transformaciones estructurales de un cuarto de siglo, R. Franco, A. León y R. Atria (Coords.), pp. 339-372. LOM, Santiago.

VÁSQUEZ, A. y M. SALGADO. 2009. Desigualdades socioeconómicas y distribución inequitativa de los riesgos ambientales en las comunas de Peñalolén y San Pedro de la Paz. Una perspectiva de justicia ambiental. Revista de Geografía Norte Grande 43: 95-110.

VÁZQUEZ, L. 1992. Ser indio otra vez. La purepechización de los tarascos serranos. CNCA, México.

VÁZQUEZ, L. 2010. Multitud y distopía. Ensayos sobre la nueva condición étnica en Michoacán. UNAM, México.

WALKER, S. 2012. Conocimiento desde adentro. Los afrosudamericanos hablan de sus pueblos y sus historias. Universidad del Cauca, Popayán.

WOLF, E. 1980 [1966]. Relaciones de parentesco, de amistad y de patronazgo en las sociedades complejas. En Antropología social de las sociedades complejas, M. Banton (Comp.), pp. 19-39. Alianza, Madrid.

YÁÑEZ, P. 2012. Ser indio en Chiloé. CNCA, Santiago.

YÁÑEZ, N. y R. MOLINA. 2008. La gran minería y los derechos indígenas en el norte de Chile. LOM, Santiago.

YÁÑEZ, N. y R. MOLINA. 2011. Las aguas indígenas en Chile. LOM, Santiago. 
